\title{
Recombinant Antithrombin Attenuates Acute Respiratory Distress Syndrome in Experimental Endotoxemia
}

Haruka Okamoto, ${ }^{*}$ Isamu Muraki, ${ }^{*}$ Hideshi Okada, ${ }^{*}$ Hiroyuki Tomita, ${ }^{\dagger}$ Kodai Suzuki, ${ }^{*}$ Chihiro Takada, ${ }^{*}$ Yugo Wakayama, ${ }^{*}$ Ayumi Kuroda, ${ }^{*}$ Hirotsugu Fukuda, ${ }^{*}$ Yuki Kawasaki, ${ }^{*}$ Ayane Nishio, ${ }^{*}$ Maho Matsuo, ${ }^{*}$ Yuto Tamaoki, ${ }^{*}$ Risa Inagawa, Shigeo Takashima, ${ }^{\ddagger}$ Toshiaki Taniguchi, ${ }^{\dagger}$ Akio Suzuki, ${ }^{\S}$ Keiko Suzuki, ${ }^{\S}$ Nagisa Miyazaki, ${ }^{\lceil}$Yoshinori Kakino, ${ }^{*}$ Ryu Yasuda, ${ }^{*}$ Tetsuya Fukuta, ${ }^{*}$ Yuichiro Kitagawa, * Takahito Miyake, * Tomoaki Doi, * Takahiro Yoshida, ${ }^{*}$ Shozo Yoshida, * and Shinji Ogura*

From the Departments of Emergency and Disaster Medicine, ${ }^{*}$ and Tumor Pathology, ${ }^{\dagger}$ Gifu University Graduate School of Medicine; the Division of Genomics Research, ${ }^{\ddagger}$ Life Science Research Center, Gifu University; the Department of Pharmacy, ${ }^{\S}$ Gifu University Hospital; and the Department of Internal Medicine, Asahi University School of Dentistry, Gifu, Japan

Accepted for publication May 20, 2021.

Address correspondence to Hideshi Okada, M.D., Ph.D., Department of Emergency and Disaster Medicine, Gifu University Graduate School of Medicine, 1-1 Yanagido, Gifu 501-1194, Japan. E-mail: hideshi@gifu-u.ac.jp.

\begin{abstract}
Sepsis-induced endothelial acute respiratory distress syndrome is related to microvascular endothelial dysfunction caused by endothelial glycocalyx disruption. Recently, recombinant antithrombin (rAT) was reported to protect the endothelial glycocalyx from septic vasculitis; however, the underlying mechanism remains unknown. Here, we investigated the effect of rAT administration on vascular endothelial injury under endotoxemia. Lipopolysaccharide (LPS; $20 \mathrm{mg} / \mathrm{kg}$ ) was injected intraperitoneally into 10week-old male C57BL/6 mice, and saline or rAT was administered intraperitoneally at 3 and 24 hours after LPS administration. Subsequently, serum and/or pulmonary tissues were examined for inflammation and cell proliferation and differentiation by histologic, ultrastructural, and microarray analyses. The survival rate was significantly higher in rAT-treated mice than in control mice 48 hours after LPS injection (75\% versus $20 \% ; P<0.05$ ). Serum interleukin-1 $\beta$ was increased but to a lesser extent in response to LPS injection in rAT-treated mice than in control mice. Lectin staining and ultrastructural studies showed a notable attenuation of injury to the endothelial glycocalyx after rAT treatment. Microarray analysis further showed an up-regulation of gene sets corresponding to DNA repair, such as genes involved in DNA helicase activity, regulation of telomere maintenance, DNA-dependent ATPase activity, and ciliary plasm, after rAT treatment. Thus, rAT treatment may promote DNA repair, attenuate inflammation, and promote ciliogenesis, thereby attenuating the acute respiratory distress syndrome caused by endothelial injury. (Am J Pathol 2021, 191: 1526-1536; https://doi.org/10.1016/ j.ajpath.2021.05.015)
\end{abstract}

The diagnostic criteria for sepsis include organ failure caused by several factors, including endothelial cell injury. ${ }^{1}$ Endothelial cells are coated by the vascular endothelial glycocalyx present on the surface of endothelial cells, which plays a pivotal role in the maintenance of vascular homeostasis. $^{2}$ In the healthy state, the glycocalyx is a critical determinant of vascular permeability.

Endothelial glycocalyx disruption causes injury to the microcirculation system, which functions to maintain blood flow and tissue perfusion, and thus, affects blood pressure and responses to inflammation. Disruption of the endothelial glycocalyx is also associated with lung injury and neutrophil adhesion during sepsis-induced acute respiratory distress

Supported in part by Ministry of Education, Science and Culture of Japan grants-in-aid for scientific research 20K17888 (R.Y.), 20K17887 (H.Okam.), 20K17857 (Y.Ki.), 20K17856 (Y.Kak.), 19H03756 (H.Okad.), 19K18347 (T.F.), 19K09410 (T.D.), 18K16511 (S.Y.), 18K08884 (T.Y.), $17 \mathrm{~K} 11569$ (S.O.), 17K17048 (H.Okam.), and 16H05497 (H.Okad.); and the Japan Blood Products Organization (S.O.). Recombinant antithrombin was provided by Kyowa Kirin, Co., Ltd.

H.Okam., I.M., and H.Okad. contributed equally to this work.

Disclosures: None declared. 
syndrome. ${ }^{5}$ Furthermore, lipopolysaccharide (LPS)-induced degradation of the endothelial glycocalyx is causally associated with microvascular endothelial dysfunction. ${ }^{6}$ Because an intact glycocalyx potentially protects against endothelial disorders, ${ }^{7-10}$ protection of the endothelial glycocalyx could represent a novel therapeutic strategy to prevent the endothelial injury-induced organ failure that occurs during sepsis. However, thus far, no clinical strategies have been established for treating sepsis through endothelial glycocalyx protection. Although corticosteroids ${ }^{11}$ and heparinoids ${ }^{12}$ have been suggested to protect the endothelial glycocalyx, definitive evidence of the clinical utility of these compounds for the treatment of sepsis is lacking.

Antithrombin (AT) - a small protein molecule that inactivates several enzymes of the coagulation system-is a physiological serine-protease inhibitor that plays a crucial role in blood coagulation. ${ }^{13}$ AT inhibits the interaction between thrombin and activated coagulation factors and has been reported to account for $75 \%$ to $80 \%$ of the inhibitory activity directed toward thrombin. ${ }^{14}$ Similarly, AT binds to heparin sulfate on endothelial cells and to syndecan-4 on neutrophils to subsequently attenuate inflammation by more than $120 \%$ of the level activated by LPS. ${ }^{15}$ AT also has been reported to attenuate endothelial glycocalyx injury caused by LPS administration, ${ }^{16}$ and a nonfucosylated recombinant AT (rAT) was found to maintain vascular structure. ${ }^{17}$ However, the mechanisms underlying these effects are unknown. Therefore, our aim was to assess the state of the pulmonary endothelial glycocalyx after LPS injection in rAT-treated mice.

\section{Materials and Methods}

\section{In Vivo Animal Studies}

The present study conformed to the NIH's Guide for the Care and Use of Laboratory Animals and was approved by the Institutional Animal Research Committee of Gifu University (30-190, Gifu, Japan). ${ }^{18}$ Ten-week-old, male C57BL/6 mice were obtained from Chubu Kagaku Shizai, Co., Ltd. (Nagoya, Japan). After a 16-hour starvation period, the mice were injected intraperitoneally with LPS $(20 \mathrm{mg} / \mathrm{kg}$; MilliporeSigma, Burlington, MA) and with rAT (750 IU/kg; Kyowa Kirin, Co., Ltd., Tokyo, Japan) for certain assays at 3 and 24 hours after LPS injection. The survival rate was evaluated every 12 hours after LPS administration; the mice that survived were euthanized, and lung specimens were obtained. There was no significant difference in the survival rate between male and female mice in a preliminary study. Therefore, male mice were used for this experiment.

\section{Serum Preparation for Enzyme-Linked Immunosorbent Assay}

Blood samples were prepared as described previously. ${ }^{19}$ Serum was collected to quantify IL-1 $\beta$ and IL-6 concentrations using Enzyme-Linked Immunosorbent Assay
Quantitation Kits for mouse IL-1 $\beta$ (MLB00C; R\&D Systems, Minneapolis, MN), and mouse IL-6 (M6000B; R\&D Systems), respectively.

\section{Histopathologic Examination}

The clinical scoring of lung was performed as described previously. ${ }^{19,20}$ These experiments were performed in a blinded manner to avoid bias (H.Okad., H.T, and T.T.).

\section{Scoring of Lectin-Staining Intensity}

For the quantitative analysis of glycocalyx injury, scoring of wheat germ agglutinin (WGA) (B-1025-5; Vector Laboratories, Burlingame, CA) staining intensity was performed using a confocal fluorescence microscope (BZ-X810; Keyence, Osaka, Japan) and ImageJ software version 1.51j8 (NIH, Bethesda, MD; http://imagej.nih.gov/ij) as described previously. ${ }^{19}$ WGA $(100 \mu \mathrm{L})$, which allows good visualization of the endothelial glycocalyx, ${ }^{21}$ was injected into the jugular vein 10 minutes before sacrifice. The lung of each mouse was embedded in Tissue-Tek O.C.T. compound (Sakura Finetek, Tokyo, Japan) and frozen with liquid nitrogen. The frozen blocks were stored at $-80^{\circ} \mathrm{C}$. Sections of frozen tissues (5- to 7- $\mu \mathrm{m}$ thick) were prepared with a cryostat. The intensity of WGA was scored manually in 10 highpower fields per sample $(n=6$ per sample) in the focal plane.

\section{Immunohistochemistry}

Deparaffinized sections (4- $\mu \mathrm{m}$ thick) were incubated with primary antibodies against Ki-67 (ab16667; Abcam, Cambridge, UK), the endothelial cell marker thrombomodulin (ab6980; Abcam), proliferating cell nuclear antigen (PCNA) (M0879; Dako, Santa Clara, CA), phosphorylated $\gamma$-H2A.X (S139. ab11174; Abcam), and ARL13B (17711-1-AP; Proteintech, Rosemond, IL). The localization of the target proteins was visualized using the VECTASTAIN Elite ABC system (Vector Laboratories) or Alexa Fluor 488-/ 568-conjugated secondary antibodies (Invitrogen, Carlsbad, CA); Hoechst staining was used to visualize nuclei.

\section{Electron Microscopy}

Electron microscopic analysis of the endothelial glycocalyx was performed as described previously. ${ }^{22}$ Because it is difficult to distinguish between the glycocalyx and nonspecific staining by osmium when the glycocalyx is visualized using lanthanum nitrate, osmium was not used in transmission electron microscopy imaging without lanthanum nitrate during glycocalyx visualization.

\section{Microarray Analysis}

Lung tissues used for microarray analysis were obtained from saline- or rAT-treated mice at 30 hours after LPS 
A

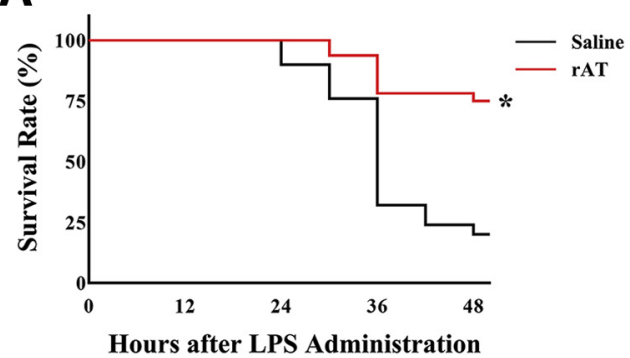

D

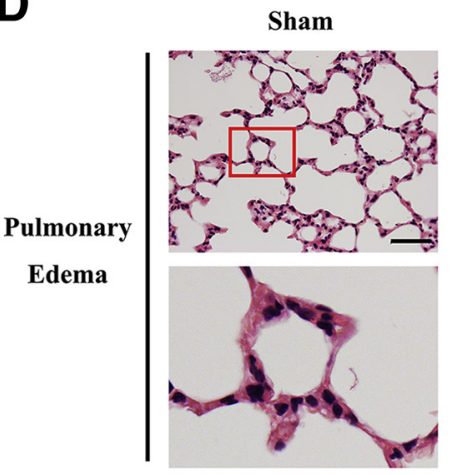

$\mathbf{F}$

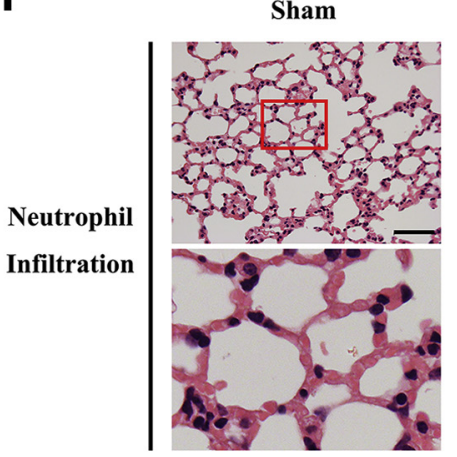

B

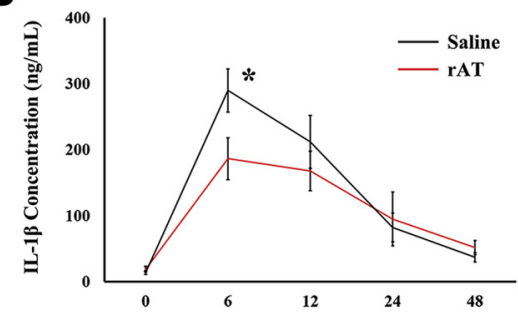

Hours after LPS Administration
C

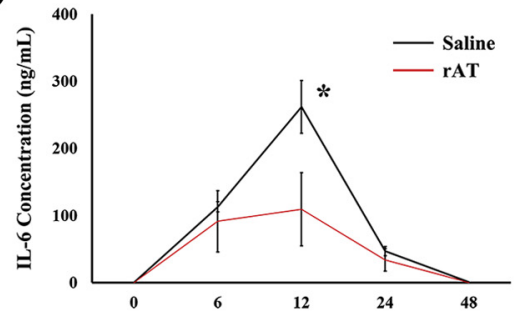

Hours after LPS Administration

E Pulmonary Edema

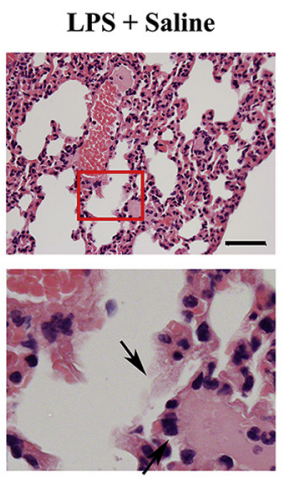

LPS + rAT
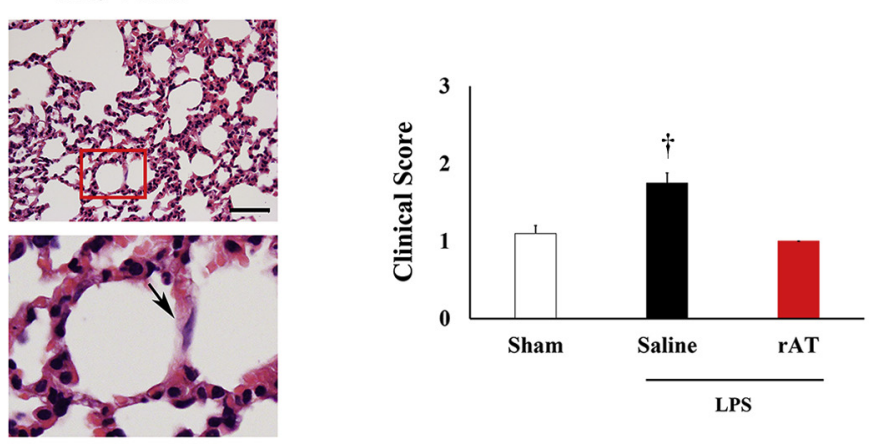

G

Neutrophil Infiltration
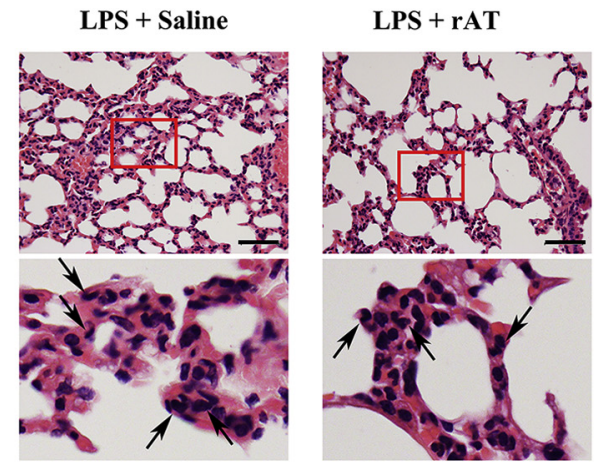

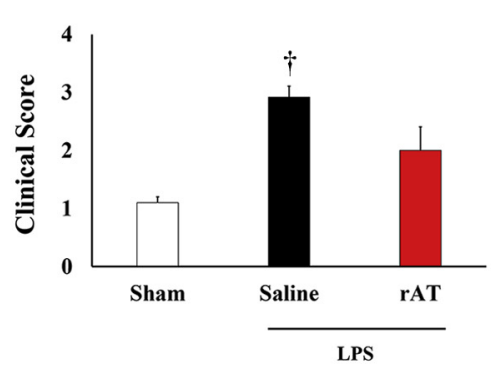

Figure 1 Recombinant antithrombin (rAT) treatment ameliorated pulmonary injury via lipopolysaccharide (LPS) administration. A: Kaplan-Meier survival curves measured for saline-injected mice $(n=50)$ and rAT-injected mice $(n=32)$ after LPS injection. B and C: Serum IL-1 $\beta(B)$ and serum IL-6 (C) concentrations in mice measured using enzyme-linked immunosorbent assay. D: Hematoxylin and eosin-stained lung tissues, with arrows indicating edema. Boxed areas in the top row are shown at higher magnification in the bottom row. E: Graph showing the histologic scoring of lung injury caused by pulmonary edema. F: Hematoxylin and eosin-stained pulmonary tissues, with arrows indicating neutrophil infiltration. Boxed areas in the top row are shown at higher magnification in the bottom row. G: Graph showing the histologic scoring of lung injury caused by pulmonary infiltration. ${ }^{*} P<0.05$ versus saline-injected mice; ${ }^{\dagger} P<0.05$ versus sham-operated mice. Scale bars: $50 \mu \mathrm{m}$ (D and $\left.\mathbf{F}\right)$.

administration, and total RNA was extracted as described previously. ${ }^{19}$ Gene expression analysis was performed by the Life Science Research Center, Gifu University (Gifu, Japan), using Agilent Expression Arrays (SurePrint G3 Mouse GE $8 \times 60 \mathrm{~K}$ microarray; Agilent, Tokyo, Japan). The obtained data were analyzed and visualized as described previously. ${ }^{19}$ All microarray data were deposited in the Gene Expression Omnibus database (https://www. ncbi.nlm.nih.gov/geo; accession number GSE160929).

\section{Statistical Analysis}

Data are presented as the means $\pm \mathrm{SEM}$. A two-tailed $t$-test was used for comparing two groups, and survival data were analyzed using the log-rank test; $P<0.05$ was considered significant. All calculations were performed using GraphPad Prism (La Jolla, CA).

\section{Results}

\section{rAT Treatment Enhances Survival after LPS \\ Administration}

To produce an experimental endotoxemia model, LPS (20 $\mathrm{mg} / \mathrm{kg}$ ) was injected intraperitoneally into 10-week-old C57BL/6 male mice. At 48 hours after LPS administration, the survival rate of rAT-treated mice $(75 \% ; 24$ of 32$)$ was significantly higher than that of control mice $(20 \% ; 10$ of 50) (Figure 1A). To confirm the adverse effects of rAT, it was injected into the mice without LPS $(n=20)$. The 

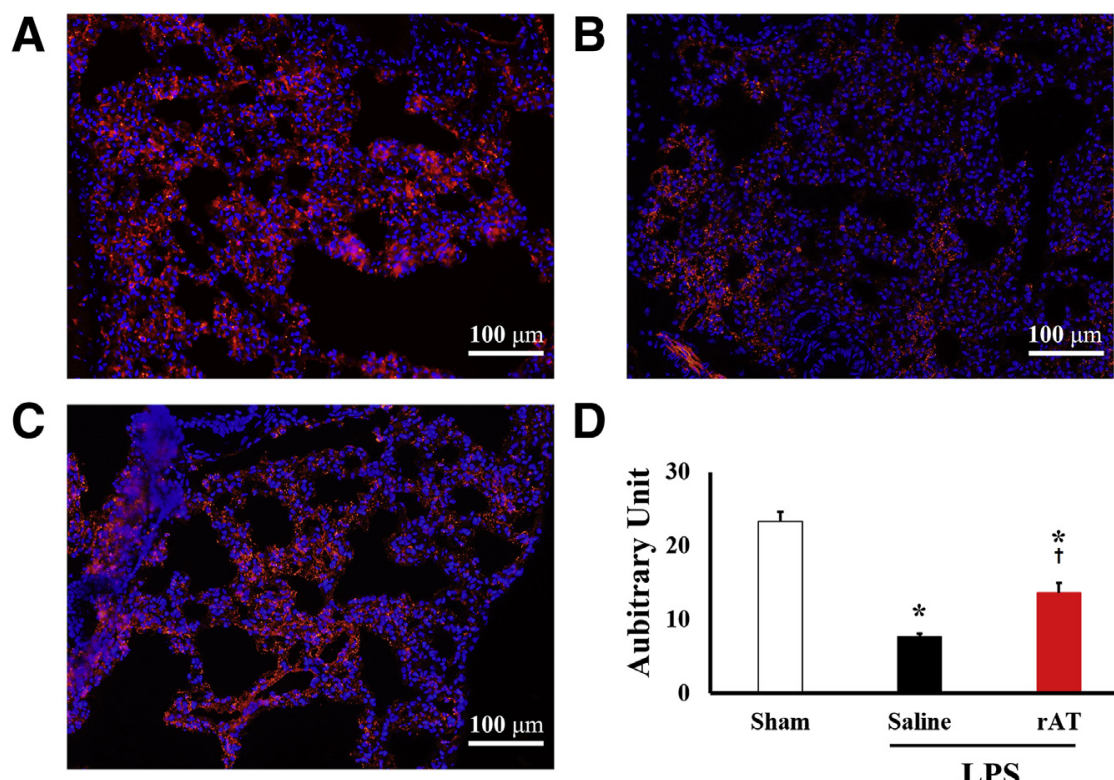

\section{D}

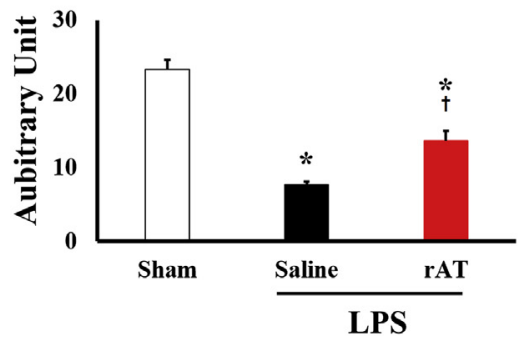

Figure 2 Recombinant antithrombin (rAT)ameliorated lipopolysaccharide (LPS)-induced endothelial glycocalyx injury. A-C: Endothelial glycocalyx-associated glycoproteins were stained with the lectin wheat germ agglutinin (WGA) after sham treatment or LPS treatment plus saline or rAT administration. D: WGA staining intensity of mouse lung tissues after sham treatment and after saline or rAT injection with LPS administration. $n=6$ in each group (D). ${ }^{*} P<0.05$ versus sham mice, ${ }^{\dagger} P<0.05$ versus mice treated with saline after LPS administration. Scale bars $=100 \mu \mathrm{m}(\mathbf{A}-\mathbf{C})$. survival rate of the rAT-injected mice was $100 \%$ at 48 hours after injection. However, adverse effects of rAT, including hemorrhage and infusion site reaction, were not documented.

In the serum of control mice, the inflammatory cytokine IL-1 $\beta$ reached concentrations of $290.0 \pm 31.6 \mathrm{ng} / \mathrm{mL}$ and $211.8 \pm 29.8 \mathrm{ng} / \mathrm{mL}$ at 6 and 12 hours after LPS injection, respectively, and then decreased to $37.1 \pm 10.7 \mathrm{ng} / \mathrm{mL}$ at 48 hours after injection (Figure 1B). However, in rAT-treated mice, the IL-1 $\beta$ concentration was significantly lower at 6 hours after LPS administration (186.3 $\pm 32.8 \mathrm{ng} / \mathrm{mL})$. Also, in rAT treated group, the IL-6 concentration $(109.3 \pm 54.6$ $\mathrm{ng} / \mathrm{mL}$ ) was siginificantly lower at 12 hours after LPS administration compared with saline injected mice (261.9 \pm $39.1 \mathrm{ng} / \mathrm{mL}$ ) (Figure 1C).

Also, in rAT treated group, the IL-6 concentration (109.3 \pm $54.6 \mathrm{ng} / \mathrm{mL}$ ) was significantly lower at 12 hours after LPS administration compared with saline injected mice (261.9 \pm $39.1 \mathrm{ng} / \mathrm{mL}$ ) (Figure 1C). Next, pulmonary injury was assessed at 48 hours after LPS injection using a clinical scoring system. ${ }^{20,23}$ Pulmonary edema and neutrophil infiltration were caused by LPS injection (Figure 1, D-G). However, at 48 hours after LPS administration, pulmonary edema was attenuated in the rAT-treated mice relative to that in the salineinjected mice (Figure 1, D and E), and neutrophil infiltration also was decreased significantly in the rAT-treated mice compared with that in the saline-injected mice (Figure 1, F and $\mathrm{G})$. These results suggest that rAT treatment attenuated the pulmonary injury that occurs after LPS administration.

\section{Pulmonary Endothelial Glycocalyx Injury Is Attenuated in rAT-Treated Mice}

WGA staining was performed to quantify endothelial glycocalyx injury, which enables the visualization of the endothelial glycocalyx, ${ }^{21}$ and measures the staining intensity. WGA staining was weaker in saline-injected mice after LPS administration than in mice not injected with LPS (sham mice) (Figure 2, A and B); however, in rATtreated mice, the WGA staining intensity after LPS injection was increased relative to that in the saline-treated mice (Figure 2, C and D). These results suggest that rAT treatment attenuated endothelial glycocalyx injury in lung capillaries.

\section{rAT Maintains Endothelial Glycocalyx Structure under Endotoxemic Conditions}

Pulmonary capillaries are classified as continuous capillaries, which are characterized by an uninterrupted endothelium and a continuous basal lamina, as observed by scanning electron microscopy (SEM) imaging (Figure 3, A and D). After LPS administration, granulocytes were detected in the pulmonary capillary lumen along with induced vasculitis, which subsequently led to the injury of the inner surface of the vascular endothelium (Figure 3, B and $\mathrm{E})$. However, rAT administration ameliorated this injury (Figure 3, C and F).

Next, to visualize the endothelial glycocalyx, SEM analysis was performed after lanthanum nitrate staining. The endothelial glycocalyx structure appeared thin and formed a continuous structure, and it covered the inner surface of the vascular endothelium in sham mice (Figure 3, G and J). After LPS injection, the endothelial glycocalyx was injured and its continuous structure was disrupted in saline-treated mice (Figure 3, $\mathrm{H}$ and $\mathrm{K}$ ), whereas the continuous structure was retained in rAT-treated mice (Figure 3, I and L).

In conventional transmission electron microscopy imaging, the inner surface of pulmonary capillaries appeared smooth and the endothelial capillary wall appeared thin in 

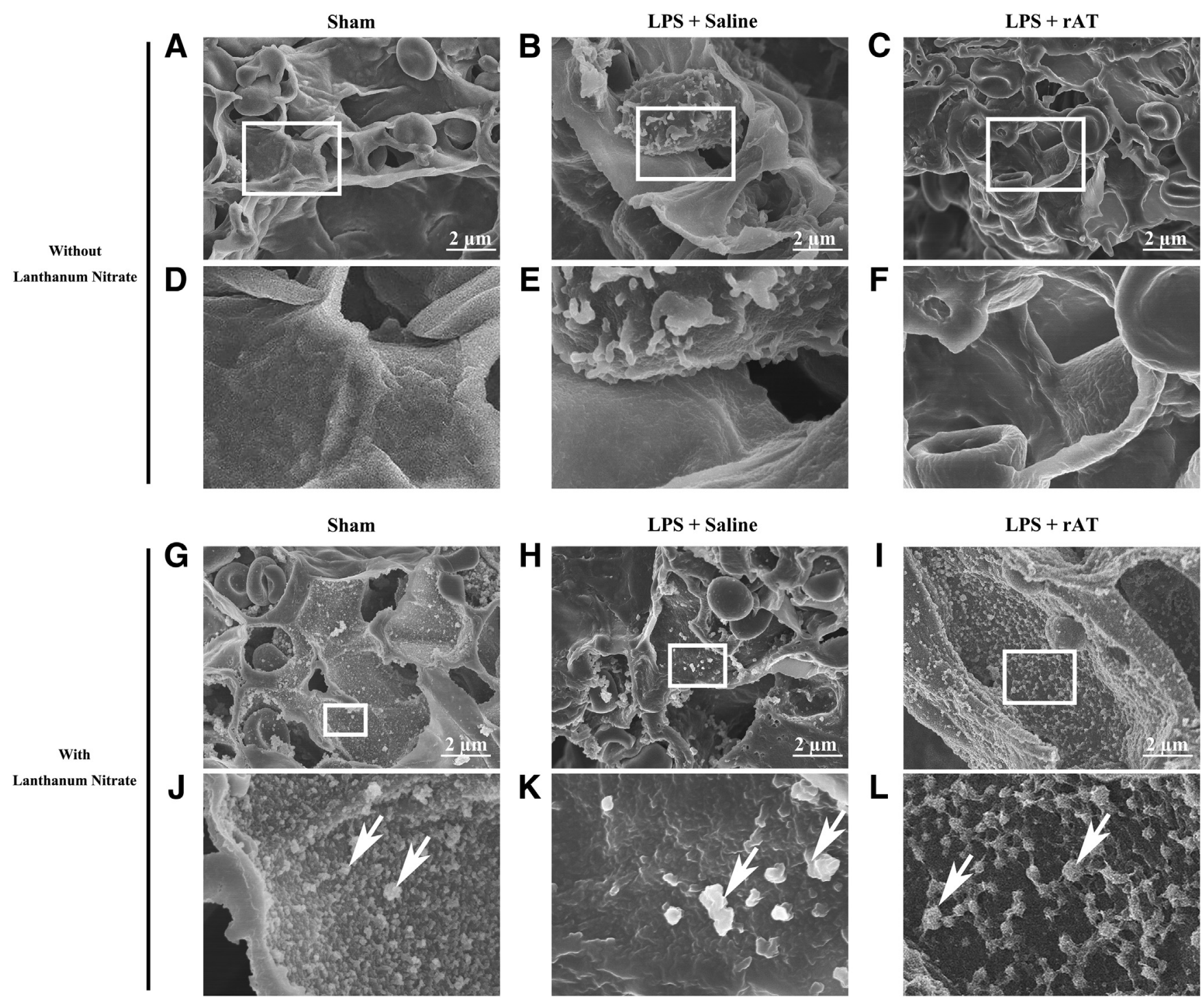

Figure 3 Recombinant antithrombin (rAT) inhibits pulmonary endothelial injury: scanning electron microscopy (SEM) analysis. Both pulmonary endothelium and endothelial glycocalyx injury were ameliorated morphologically to a greater extent via rAT treatment. A-F: Conventional SEM imaging (without lanthanum nitrate) of the pulmonary endothelium in sham mice (A and $\mathbf{D})$ and in mice injected with saline (B and $\mathbf{E})$ or rAT (C and $\mathbf{F})$ after lipopolysaccharide (LPS) administration. D-F: Magnified images of boxed areas in panels A-C. G-L: SEM imaging (with lanthanum nitrate) of the glycocalyx in sham mice (G and $\mathbf{J}$ ) and in mice injected with saline ( $\mathbf{H}$ and $\mathbf{K}$ ) or rAT (I and $\mathbf{L}$ ) after LPS administration. $\mathbf{J}-\mathbf{L}$ : Magnified images of boxed areas in panels $\mathbf{G}-\mathbf{I}$. White arrows indicate lanthanum nitrate-stained endothelial glycocalyx. Scale bars $=2 \mu \mathrm{m}(\mathbf{A}-\mathbf{C}$ and $\mathbf{G}-\mathbf{I})$.

sham mice (Figure 4, A and D). After LPS administration, the inner surface of the vascular endothelium changed and showed a rough appearance and the endothelial wall became edematous in saline-treated mice (Figure 4, B and E), whereas LPS-induced endothelial edema was attenuated in rAT-treated mice (Figure 4, C and F).

Transmission electron microscopy analyses further indicated that the endothelial glycocalyx forms a continuous structure and covers the inner surface of the vascular endothelium (Figure 4, G and J), as also observed in SEM imaging. After LPS injection, the endothelial glycocalyx was degraded, and, thus, the continuous structure was damaged in saline-treated mice (Figure 4, H and K). However, in rAT-treated mice, the continuous structure was retained and the endothelial glycocalyx injury was ameliorated (Figure 4, I and L). These results show that rAT treatment ameliorated endothelial glycocalyx injury under endotoxemia.

\section{Gene Set Enrichment Analysis of rAT Treatment in Lungs}

Gene set enrichment analysis was performed on salinetreated (control) and rAT-treated mice. In gene ontology and Kyoto Encyclopedia of Genes and Genomes analyses of gene set enrichment analysis, a significant up-regulation of gene sets related to DNA helicase activity (Figure 5A) was observed, along with regulation of telomere maintenance 

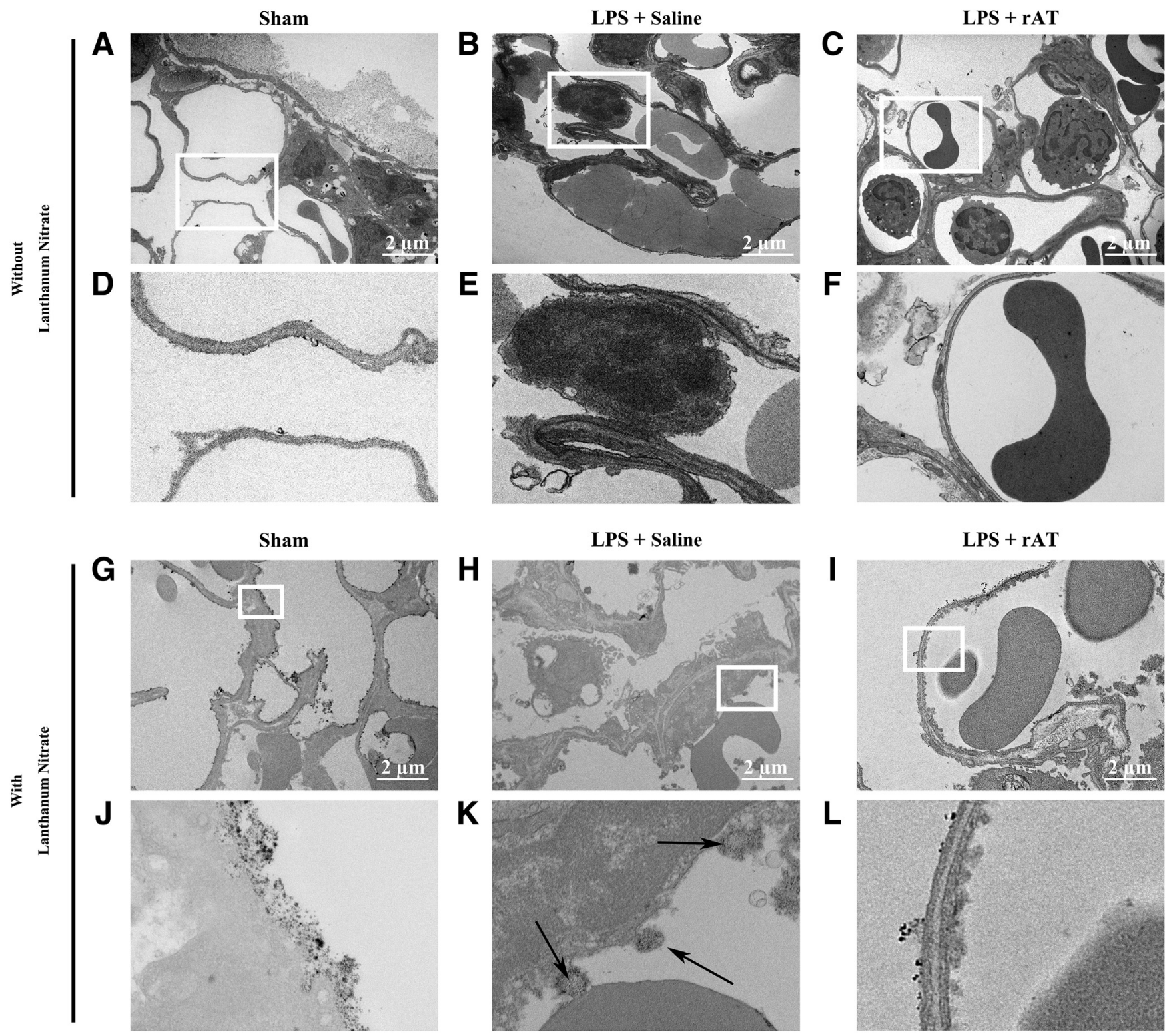

Figure 4 Recombinant antithrombin ( $\mathrm{rAT}$ ) treatment attenuates pulmonary endothelial injury: transmission electron microscopy (TEM) analysis. Both pulmonary endothelium and endothelial glycocalyx injury were ameliorated morphologically to a greater extent via rAT treatment. A-F: Conventional TEM imaging (without lanthanum nitrate) of pulmonary endothelium in sham mice (A and $\mathbf{D})$ and in mice injected with saline (B and $\mathbf{E})$ or rAT (C and $\mathbf{F})$ after lipopolysaccharide (LPS) administration. D-F: Magnified images of boxed areas in panels A-C. G-L: TEM imaging (with lanthanum nitrate) of the glycocalyx in sham mice ( $\mathbf{G}$ and $\mathbf{J}$ ) and in mice injected with saline ( $\mathbf{H}$ and $\mathbf{K})$ or rAT ( $\mathbf{I}$ and $\mathbf{L})$ after LPS administration. $\mathbf{J}-\mathbf{L}$ : Magnified images of boxed areas in panels $\mathbf{G}-\mathbf{I}$. Black arrows indicate residue of the glycocalyx. Scale bars $=2 \mu \mathrm{m}(\mathbf{A}-\mathbf{C}$ and $\mathbf{G}-\mathbf{I})$.

(Figure 5B), DNA-dependent ATPase activity (Figure 5C), and ciliary plasm (Figure 5D) in rAT-treated mice $(P<0.01$ versus control). Collectively, these results indicate that rAT treatment against LPS-induced vasculitis functionally influenced DNA repair.

\section{DNA Repair in Pulmonary Capillaries}

Ki-67 expression was examined because the gene set enrichment analysis results indicated that rAT treatment could affect cell proliferation/differentiation. Ki-67 was expressed at a higher level in rAT-treated mice after LPS injection than in saline-treated mice after LPS administration and in sham mice (Figure 6, A-D) and was detected in several types of cells such as inflammatory cells, alveolar macrophages, and endothelial cells. Therefore, for further confirmation, double immunostaining for Ki-67 and thrombomodulin, a marker of endothelial cells, was performed, which showed colocalization of $\mathrm{Ki}-67$ and thrombomodulin expression in rAT-treated mice (Figure 6E).

To further confirm the DNA repair, immunofluorescence assays were performed with staining for PCNA and 

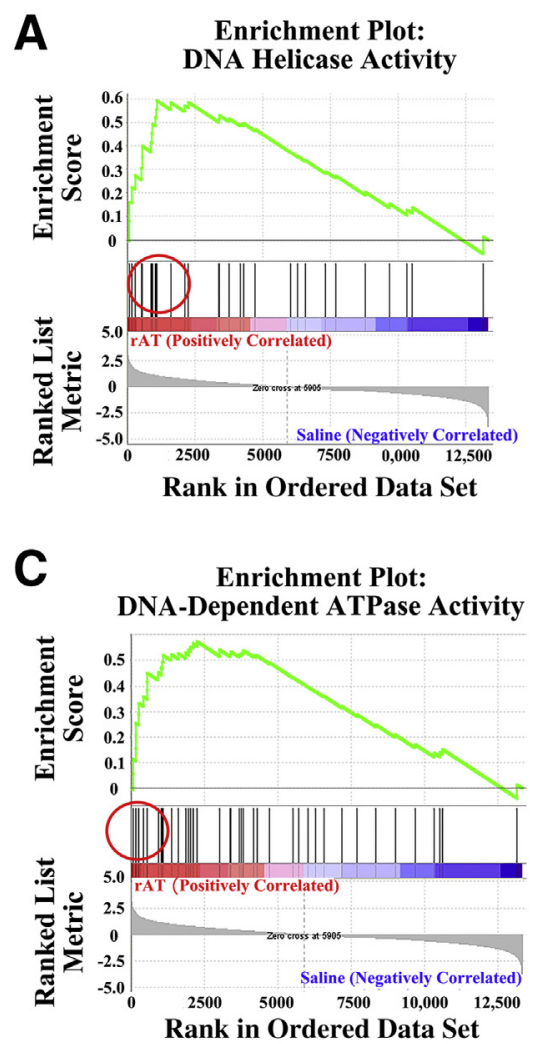

$$
\begin{aligned}
& P=0.000 \\
& \text { NES }=1.69
\end{aligned}
$$

Leading Edge Genes

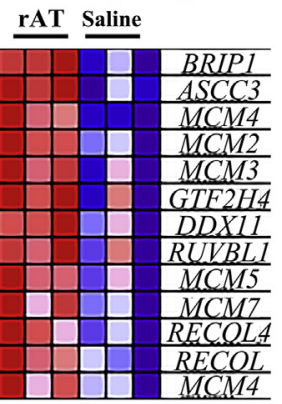

$P=0.00$

NES $=1.68$

Leading Edge Genes

rAT Saline

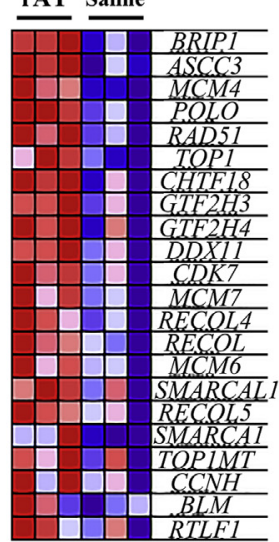

B

Enrichment Plot: $\quad P=0.000$

Regulation of Telomere Maintenance NES $=1.65$

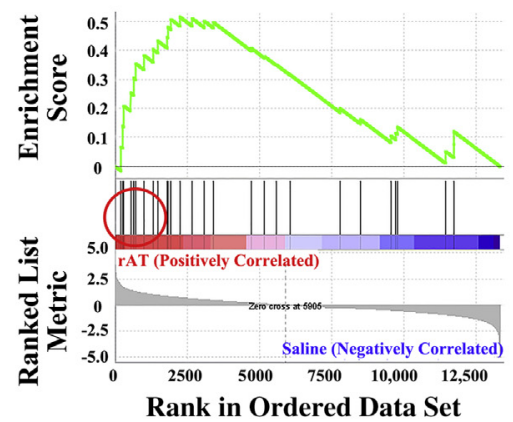

Leading Edge Genes
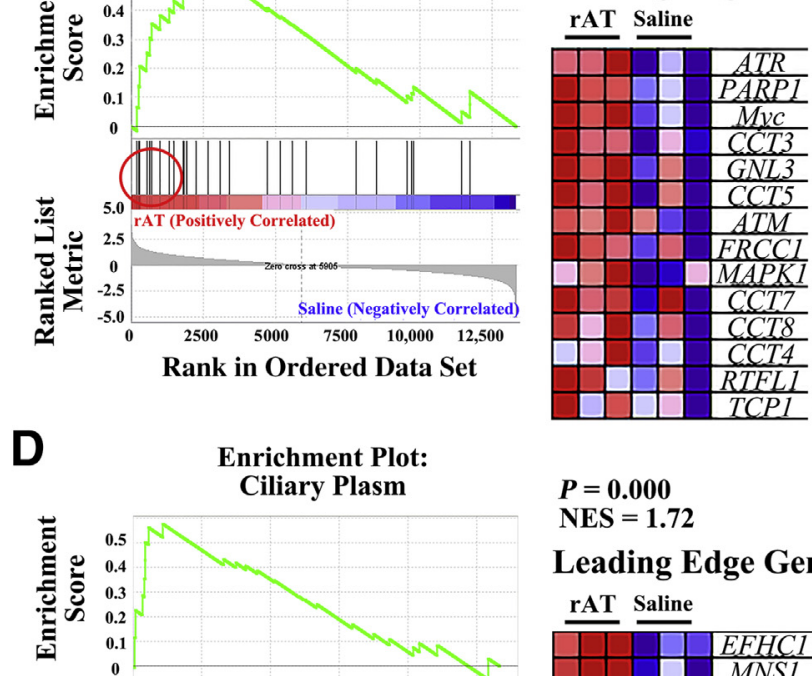

$P=0.000$

NES $=1.72$

Leading Edge Genes rAT Saline

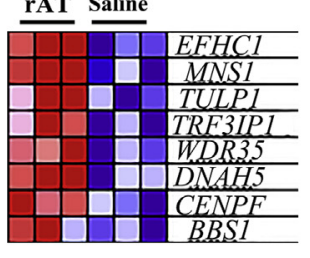

Figure 5 Gene set enrichment analysis. Enrichment plots and leading-edge gene lists. A: DNA helicase activity. B: Regulation of telomere maintenance. C: DNA-dependent ATPase activity. D: Ciliary plasm. Red circles indicate leading edge genes. NES, normalized enrichment score; rAT, recombinant antithrombin.

phosphorylated $\gamma$-H2A.X. PCNA is a protein participating in the replication and repair of DNA, and the adjustment of the cell cycle. ${ }^{24}$ Phosphorylated $\gamma$-H2A.X is related to the activation of the local DNA damage repair pathway. ${ }^{25}$ PCNApositive cell numbers in rAT-treated mice were larger compared with those in the saline-treated group (Figure 7, A and B). Furthermore, in rAT-treated mice, phosphorylated $\gamma$ H2A.X-positive cell numbers were much larger than those in the saline group (Figure 7, C and D). PCNA-positive cells and especially phosphorylated $\gamma$-H2A.X-positive cells include several types of cells, not only endothelial cells, which show flat nuclei (Figure 7, A-D).

Lastly, ARL13B immunostaining was performed to assess the gene set related to ciliary proteins. Immunohistochemical staining with an ARL13B-specific antibody showed that ARL13B expression was localized to tracheal epithelial cells (Figure 7E). After LPS injection, in rATtreated mice, the cilia (ARL13B-positive) existed continuously on tracheal cells, whereas the structure of the cilia layer was injured and eroded (Figure 7E) in the salinetreated group. These results showed that rAT treatment attenuated cilial injury on tracheal cells after LPS injection.

\section{Discussion}

This study showed that compared with saline treatment, rAT treatment ameliorated pulmonary endothelial glycocalyx injury in mice after LPS injection. Although previous studies have shown that rAT shows anti-inflammatory effects, ${ }^{16,17}$ the novel insight of the present study is that rAT administration causes the acceleration of DNA repair via enhancement of DNA helicase activity, regulation of telomere maintenance, and DNA-dependent ATPase activity.

\section{Anti-Inflammatory Effect of rAT}

The results of this study showed that rAT treatment decreased the levels of the inflammatory cytokine IL-1 $\beta$ and inhibited neutrophil infiltration in the lung. These findings are in agreement with those of previous work indicating that AT ameliorates inflammation by interacting with endothelial cells and neutrophils. ${ }^{15}$

Neutrophils play a crucial role in endothelial injury. Sepsis causes modification of neutrophil entrapment and neutrophil deformability in pulmonary capillaries, and 
A

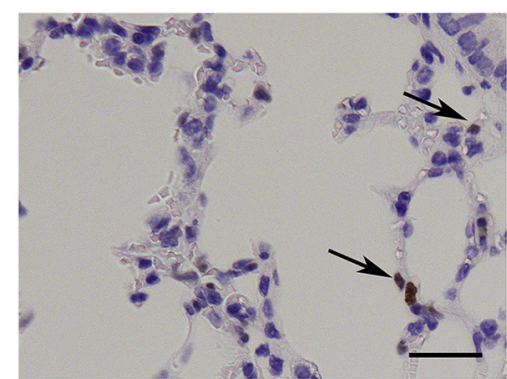

C

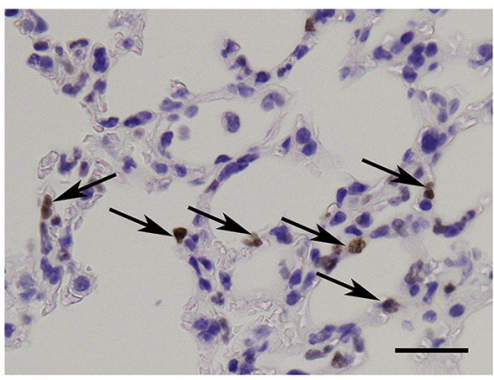

E
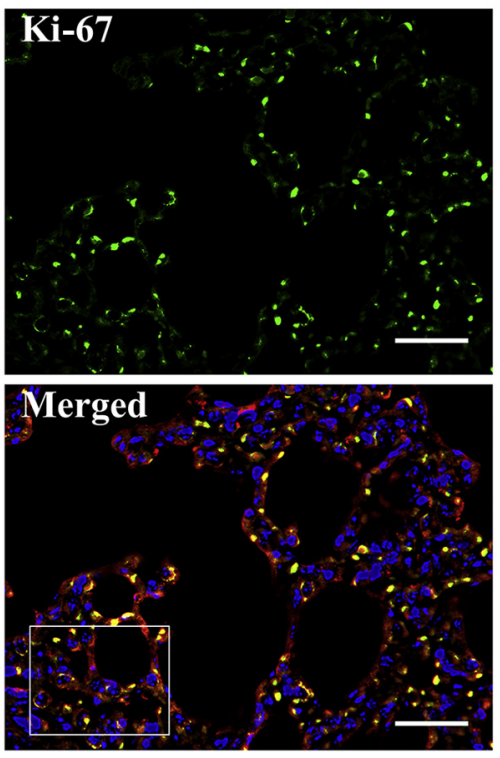

B

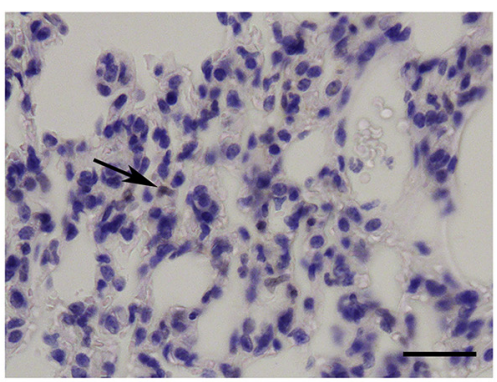

D
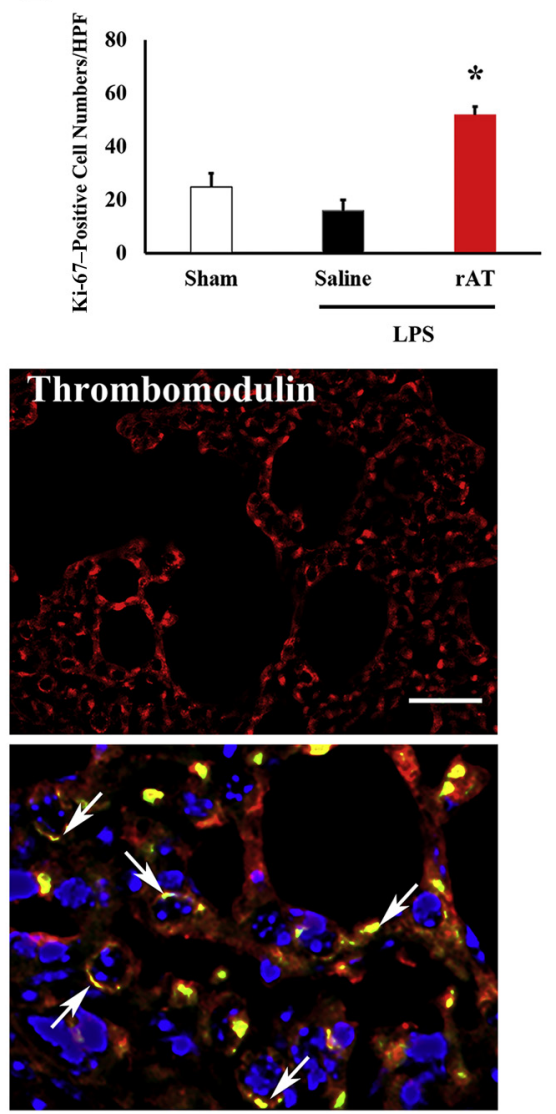

Figure 6 Immunohistochemical analysis of Ki67. A-C: Representative images of the immunohistochemical staining of $\mathrm{Ki}-67$ in the lungs of sham mice (A) and mice treated with saline (B) or recombinant antithrombin (rAT) (C) after lipopolysaccharide (LPS) administration. Black arrows indicate Ki-67-positive cells. D: Graph showing the number of Ki-67-positive cells. E: Doubleimmunofluorescence staining of Ki-67 and thrombomodulin. Bottom right panel: Expanded view of the boxed area in the merged image. White arrows indicate colocalization of $\mathrm{Ki}-67$ and thrombomodulin expression in endothelial cells, which show flat nuclei. ${ }^{*} P<0.05$ versus sham mice. Scale bars: $20 \mu \mathrm{m}$ (B and C); $50 \mu \mathrm{m}$ (E). HPF, highpower field. neutrophil entrapment is followed by hyperpermeability of the lung capillaries and edema formation. ${ }^{26,27}$ Moreover, in acute respiratory distress syndrome, a pathologic alteration secondary to sepsis is the recruitment of neutrophils in the lung. ${ }^{28}$ Conversely, neutrophil disruption ameliorates organ failure by attenuating endothelial injury under septic conditions. ${ }^{29,30}$ Although the endothelial glycocalyx is present on healthy endothelial cells and plays a critical role in vascular homeostasis, $2,22,31-35$ neutrophils and secreted cytokines injure the endothelial glycocalyx and subsequently cause organ failure. A previous study also indicated that disruption of the endothelial glycocalyx affects the pathogenesis of acute respiratory distress syndrome. ${ }^{5}$

Prostacyclin-2 production from endothelial cells is promoted through binding with AT and heparan sulfate on endothelial cells. Prostacyclin-2 inhibits inflammatory cytokine secretion and binding to endothelial cells and neutrophils. Furthermore, AT binds to syndecan-4 on the surface of neutrophils and subsequently inhibits neutrophil migration. ${ }^{13,15}$ Similarly, AT was reported to inhibit the secretion of IL-6, IL-8, and p-selectin from endothelial cells by acting through protease-activated receptors. Moreover, AT was found to attenuate acute lung injury by decreasing high mobility group box 1 production. $^{36}$

Our study here showed that rAT treatment inhibited the endothelial glycocalyx injury that occurs with LPS-induced endotoxemia. Because attenuation of inflammation might protect the endothelial glycocalyx structure, ${ }^{29,30}$ the antiinflammatory effect of $\mathrm{rAT}$ can be regarded as one of the beneficial effects of rAT treatment targeting LPS-induced vasculitis. 


\section{A}

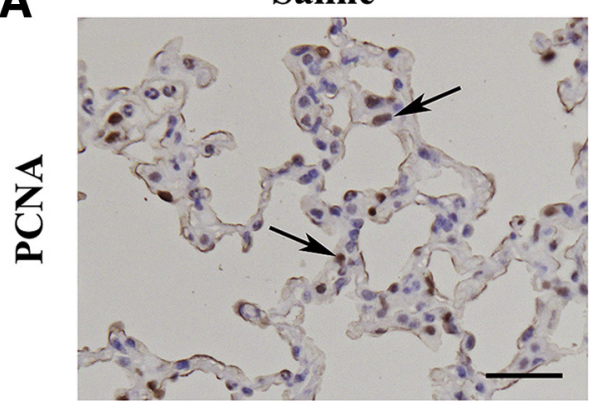

C
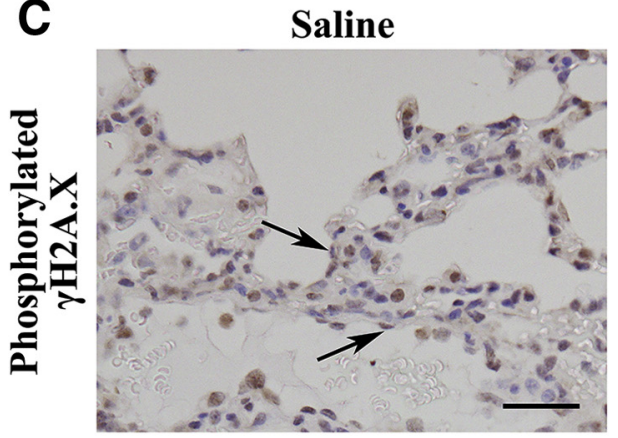

rAT

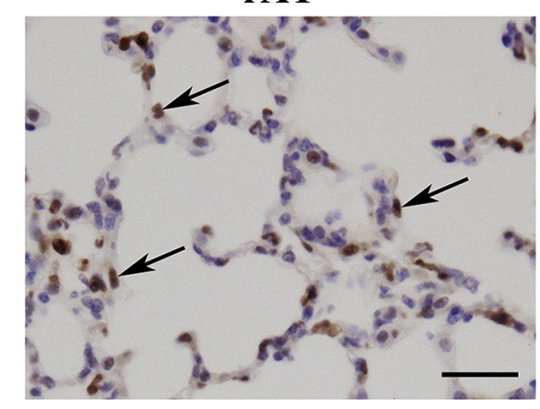

rAT

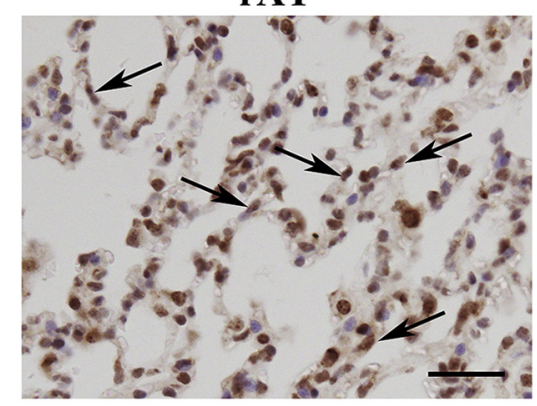

B

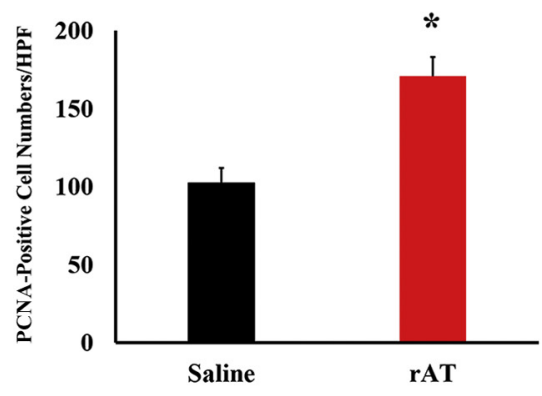

D

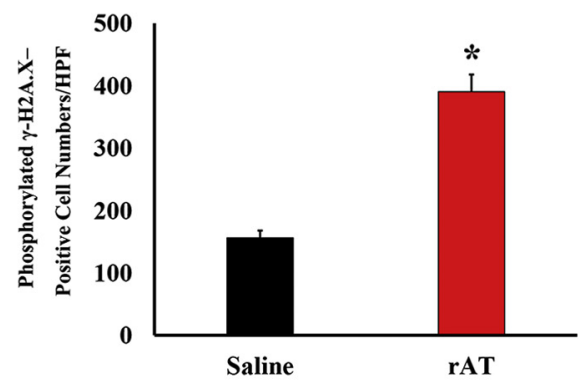

E

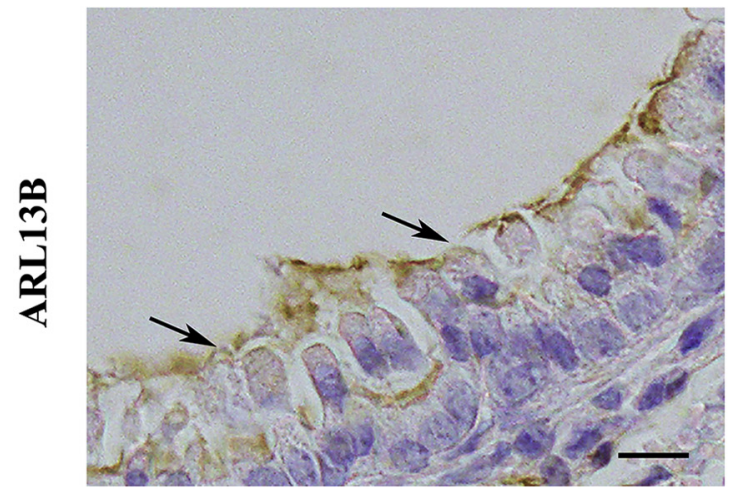

rAT

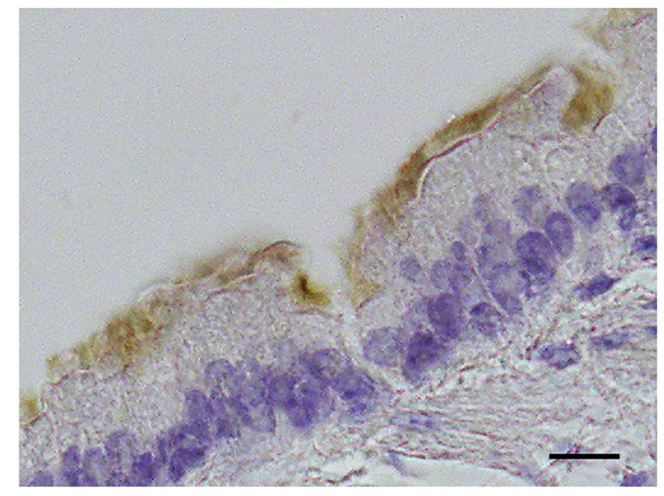

Figure 7 Immunohistochemical analysis of proliferating cell nuclear antigen (PCNA), phosphorylated $\gamma$ H2A.X, and ARL13B. A: Representative images of the immunohistochemical staining of PCNA in the lungs of saline-treated mice (left panel) and mice treated with recombinant antithrombin (rAT) (right panel) after lipopolysaccharide (LPS) administration. Arrows indicate PCNA-positive cells, which show flat nuclei. These cells are presumed to be endothelial cells. B: Graph showing the number of PCNA-positive cells. C: Representative images of the immunohistochemical staining of phosphorylated $\gamma \mathrm{H} 2 \mathrm{~A}$.X in the lungs of saline-treated mice (left panel) and mice treated with rAT (right panel) after LPS administration. Arrows indicate $\gamma$ H2A.X-phosphorylated cells, which show flat nuclei. These cells are presumed to be endothelial cells. D: Graph showing the number of $\gamma$ H2A.X-phosphorylated cells. E: Representative images of the immunohistochemical staining of ARL13B in the lungs of saline-treated mice (left panel) and mice treated with rAT (right panel) after LPS administration. Arrows indicate erosion by injury of cilia on the respiratory epithelium covering the respiratory tract. ${ }^{*} P<0.05$ versus saline-treated mice. Scale bars: $50 \mu \mathrm{m}$ (A and C); $20 \mu \mathrm{m}$ (E). HPF, high-power field.

\section{Endothelial Cell Repair by rAT}

The occurrence of accelerated DNA repair after rAT administration was supported by the results of our gene ontology analyses, which showed the up-regulation of gene sets related to DNA helicase activity, regulation of telomere maintenance, and DNA-dependent ATPase activity in rAT-treated mice. Ki-67, which is related to the cell cycle, was expressed at higher levels in pulmonary endothelial cells in rAT-treated mice than in untreated mice. These findings suggest that DNA repair was promoted more strongly in endothelial cells in rAT-treated mice than in control mice. Endogenous cellular processes cause several types of DNA damage, including oxidation of bases, generation of DNA strand interruptions by reactive oxygen species, hydrolysis of bases, alkylation of bases, and 
mismatch of bases. In acute respiratory distress syndrome, neutrophils migrate to the lungs, secrete reactive oxygen species and inflammatory cytokines, and, ultimately, cause pulmonary tissue injury. ${ }^{37}$ Thus, although the DNA of endothelial cells is injured under endotoxemia, rAT treatment might promote DNA repair.

PCNA is a protein involved in the replication and repair of DNA and the adjustment of the cell cycle. ${ }^{24}$ Phosphorylated $\gamma-\mathrm{H} 2 \mathrm{~A}$.X is related to the activation of the local DNA damage repair pathway. ${ }^{25}$ rAT treatment increases the PCNA-positive cell number and $\gamma$-H2A.X phosphorylation, along with increasing the levels of Ki-67-positive cells. Because these molecules are integral to DNA repair, these results suggest that rAT treatment may accelerate DNA repair in several cell types in the lungs.

rAT treatment attenuated endothelial glycocalyx injury caused by septic vasculitis. Because the endothelial glycocalyx exists on the surface of endothelial cells and is synthesized by endothelial cells ${ }^{38}$ DNA repair of endothelial cells might be closely associated with endothelial glycocalyx synthesis in septic vasculitis.

rAT treatment also up-regulated the gene set related to ciliary plasm. Cilia are organelles present in eukaryotic cells that are shaped like slender protuberances and are classified into two types: motile and nonmotile. Motile cilia exist on the respiratory epithelium covering the respiratory tract, where they serve in the mucociliary clearance that sweeps mucus and dirt out of the lungs. ${ }^{39}$ The current results showed that cilia were present on the respiratory epithelium lining the respiratory tract and that rAT treatment might affect respiratory epithelial cells and influence the repair of cilia. Because nonmotile cilia (primary cilia) are present on almost all types of cells, excluding blood cells, the upregulation of the gene set related to ciliary plasm also could be affected by endothelial primary cilia. However, clarification of this matter requires further investigation.

\section{Study Limitation}

Sepsis is a complex disease compared with the LPS-induced simple endotoxemia that developed in an experimental model. The focus of the current study was to investigate the direct relationship between septic vasculitis and endothelial glycocalyx injury. Thus, we used an endotoxemia model. However, this animal model does not mimic certain typical septic conditions, such as bacterial infection. This represents a limitation of our study. In addition, because alveolar epithelial cells, the basement membrane, and endothelial cells make three tightly bound layers, it is difficult to completely distinguish them using a light microscope. Furthermore, we analyzed gene expression using RNA isolated from total lung. For further confirmation about the location of the gene expression, future study is required. This study also did not investigate the adverse effects of rAT in healthy mice. Because the endothelium appears normal in healthy mice, it is possible that rAT did not cause adverse effects such as hemorrhage or infusion site reactions.

\section{Conclusions}

Treatment with rAT protects the endothelial glycocalyx (which is essential for vascular homeostasis) against injury by both inhibiting the damage caused by several factors including anti-inflammation and accelerating the restoration of endothelial cells. Because rAT already is used in clinical applications, its administration can be regarded as a novel strategy for the treatment of septic vasculitis.

\section{Acknowledgments}

We thank Yasuko Nogaki and Shoko Kumazaki for technical assistance.

\section{Author Contributions}

H.Okam. and H.Okad. wrote the manuscript; C.T., R.Y., Y.Kaw., and N.M. performed transmission electron microscopy (TEM) imaging; I.M., H.Okad., Ko.S., Y.W., A.K., and H.F. performed scanning electron microscopy (SEM) imaging; C.T., T.Y., and S.Y. prepared samples for TEM imaging; I.M., A.K., H.F., and Y.T. prepared samples for SEM imaging; T.F., Y.Ki., H. Okam., A.N., and M.M. performed animal studies; H.T., A.S., Ke.S., and T.D. assessed the histologic scores and cell counts; R.I., T.T., and H.T. performed the intensity score study; Y.Kak., S.T., and S.Y. performed microarray analyses; H.Okad., T.F., H.T., and S.T. performed gene set enrichment analysis; S.O. supervised the animal studies; and H.Okad. revised and edited the manuscript; all authors read and approved the final manuscript.

\section{References}

1. Singer M, Deutschman CS, Seymour CW, Shankar-Hari M, Annane D, Bauer M, Bellomo R, Bernard GR, Chiche JD, Coopersmith CM, Hotchkiss RS, Levy MM, Marshall JC, Martin GS, Opal SM, Rubenfeld GD, van der Poll T, Vincent JL, Angus DC: The third international consensus definitions for sepsis and septic shock (Sepsis-3). JAMA 2016, 315:801-810

2. Chelazzi C, Villa G, Mancinelli P, De Gaudio AR, Adembri C: Glycocalyx and sepsis-induced alterations in vascular permeability. Crit Care 2015, 19:26

3. Henry CB, Duling BR: Permeation of the luminal capillary glycocalyx is determined by hyaluronan. Am J Physiol 1999, 277: H508-H514

4. Vink H, Duling BR: Capillary endothelial surface layer selectively reduces plasma solute distribution volume. Am J Physiol Heart Circ Physiol 2000, 278:H285-H289

5. Schmidt EP, Yang Y, Janssen WJ, Gandjeva A, Perez MJ, Barthel L, Zemans RL, Bowman JC, Koyanagi DE, Yunt ZX, Smith LP, Cheng SS, Overdier KH, Thompson KR, Geraci MW, Douglas IS, Pearse DB, Tuder RM: The pulmonary endothelial glycocalyx 
regulates neutrophil adhesion and lung injury during experimental sepsis. Nat Med 2012, 18:1217-1223

6. Inagawa R, Okada H, Takemura G, Suzuki K, Takada C, Yano H, Ando Y, Usui T, Hotta Y, Miyazaki N, Tsujimoto A, Zaikokuji R, Matsumoto A, Kawaguchi T, Doi T, Yoshida T, Yoshida S, Kumada K, Ushikoshi H, Toyoda I, Ogura S: Ultrastructural alteration of pulmonary capillary endothelial glycocalyx during endotoxemia. Chest 2018, 154:317-325

7. Eskens BJ, Zuurbier CJ, van Haare J, Vink H, van Teeffelen JW: Effects of two weeks of metformin treatment on whole-body glycocalyx barrier properties in $\mathrm{db} / \mathrm{db}$ mice. Cardiovasc Diabetol 2013, 12: 175

8. Frati-Munari AC: [Medical significance of endothelial glycocalyx]. Arch Cardiol Mex 2013, 83:303-312

9. Gunst J, Derese I, Aertgeerts A, Ververs EJ, Wauters A, Van den Berghe G, Vanhorebeek I: Insufficient autophagy contributes to mitochondrial dysfunction, organ failure, and adverse outcome in an animal model of critical illness. Crit Care Med 2013, 41:182-194

10. Nieuwdorp M, van Haeften TW, Gouverneur MC, Mooij HL, van Lieshout MH, Levi M, Meijers JC, Holleman F, Hoekstra JB, Vink H, Kastelein JJ, Stroes ES: Loss of endothelial glycocalyx during acute hyperglycemia coincides with endothelial dysfunction and coagulation activation in vivo. Diabetes 2006, 55:480-486

11. Chappell D, Hofmann-Kiefer K, Jacob M, Rehm M, Briegel J, Welsch U, Conzen P, Becker BF: TNF-alpha induced shedding of the endothelial glycocalyx is prevented by hydrocortisone and antithrombin. Basic Res Cardiol 2009, 104:78-89

12. Song JW, Zullo JA, Liveris D, Dragovich M, Zhang XF, Goligorsky MS: Therapeutic restoration of endothelial glycocalyx in sepsis. J Pharmacol Exp Ther 2017, 361:115-121

13. Rosenberg RD, Damus PS: The purification and mechanism of action of human antithrombin-heparin cofactor. J Biol Chem 1973, 248: 6490-6505

14. Stein PE, Carrell RW: What do dysfunctional serpins tell us about molecular mobility and disease? Nat Struct Biol 1995, 2:96-113

15. Wiedermann CJ: Clinical review: molecular mechanisms underlying the role of antithrombin in sepsis. Crit Care 2006, 10:209

16. Iba T, Levy JH, Hirota T, Hiki M, Sato K, Murakami T, Nagaoka I: Protection of the endothelial glycocalyx by antithrombin in an endotoxin-induced rat model of sepsis. Thromb Res 2018, 171:1-6

17. Iba T, Hirota T, Sato K, Nagaoka I: Protective effect of a newly developed fucose-deficient recombinant antithrombin against histoneinduced endothelial damage. Int J Hematol 2018, 107:528-534

18. Committee for the Update of the Guide for the Care and Use of Laboratory AnimalsNational Research Council: Guide for the Care and Use of Laboratory Animals: Eighth Edition. Washington, DC, National Academies Press, 2011

19. Suzuki K, Okada H, Takemura G, Takada C, Tomita H, Yano H, Muraki I, Zaikokuji R, Kuroda A, Fukuda H, Nishio A, Takashima S, Suzuki A, Miyazaki N, Fukuta T, Yamada N, Watanabe T, Doi T, Yoshida T, Kumada K, Ushikoshi H, Yoshida S, Ogura S: Recombinant thrombomodulin protects against LPS-induced acute respiratory distress syndrome via preservation of pulmonary endothelial glycocalyx. Br J Pharmacol 2020, 177:4021-4033

20. Langlois RA, Meyerholz DK, Coleman RA, Cook RT, Waldschmidt TJ, Legge KL: Oseltamivir treatment prevents the increased influenza virus disease severity and lethality occurring in chronic ethanol consuming mice. Alcohol Clin Exp Res 2010, 34: 1425-1431

21. Kataoka H, Ushiyama A, Kawakami H, Akimoto Y, Matsubara S, Iijima T: Fluorescent imaging of endothelial glycocalyx layer with wheat germ agglutinin using intravital microscopy. Microsc Res Tech 2016, 79:31-37

22. Okada H, Takemura G, Suzuki K, Oda K, Takada C, Hotta Y, Miyazaki N, Tsujimoto A, Muraki I, Ando Y, Zaikokuji R, Matsumoto A, Kitagaki H, Tamaoki Y, Usui T, Doi T, Yoshida T, Yoshida S, Ushikoshi H, Toyoda I, Ogura S: Three-dimensional ultrastructure of capillary endothelial glycocalyx under normal and experimental endotoxemic conditions. Crit Care 2017, 21:261

23. Meyerholz DK, Edsen-Moore M, McGill J, Coleman RA, Cook RT, Legge KL: Chronic alcohol consumption increases the severity of murine influenza virus infections. J Immunol 2008, 181:641-648

24. Tsuji Y, Watanabe K, Araki K, Shinohara M, Yamagata Y, Tsurimoto T, Hanaoka F, Yamamura K, Yamaizumi M, Tateishi S: Recognition of forked and single-stranded DNA structures by human RAD18 complexed with RAD6B protein triggers its recruitment to stalled replication forks. Genes Cells 2008, 13:343-354

25. Sone K, Piao L, Nakakido M, Ueda K, Jenuwein T, Nakamura Y, Hamamoto R: Critical role of lysine 134 methylation on histone $\mathrm{H} 2 \mathrm{AX}$ for gamma-H2AX production and DNA repair. Nat Commun 2014, 5:5691

26. Wiener-Kronish JP, Albertine KH, Matthay MA: Differential responses of the endothelial and epithelial barriers of the lung in sheep to Escherichia coli endotoxin. J Clin Invest 1991, 88:864-875

27. Wiggs BR, English D, Quinlan WM, Doyle NA, Hogg JC, Doerschuk CM: Contributions of capillary pathway size and neutrophil deformability to neutrophil transit through rabbit lungs. J Appl Physiol (1985) 1994, 77:463-470

28. Grommes J, Soehnlein O: Contribution of neutrophils to acute lung injury. Mol Med 2011, 17:293-307

29. Fukuta T, Okada H, Takemura G, Suzuki K, Takada C, Tomita H, Suzuki A, Oda K, Uchida A, Matsuo S, Fukuda H, Yano H, Muraki I, Zaikokuji R, Kuroda A, Nishio A, Sampei S, Miyazaki N, Hotta Y, Yamada N, Watanabe T, Morishita K, Doi T, Yoshida T, Ushikoshi H, Yoshida S, Maekawa Y, Ogura S: Neutrophil elastase inhibition ameliorates endotoxin-induced myocardial injury accompanying degradation of cardiac capillary glycocalyx. Shock 2020, 54: 386-393

30. Suzuki K, Okada H, Takemura G, Takada C, Kuroda A, Yano H, Zaikokuji R, Morishita K, Tomita H, Oda K, Matsuo S, Uchida A, Fukuta T, Sampei S, Miyazaki N, Kawaguchi T, Watanabe T, Yoshida T, Ushikoshi H, Yoshida S, Maekawa Y, Ogura S: Neutrophil elastase damages the pulmonary endothelial glycocalyx in lipopolysaccharide-induced experimental endotoxemia. Am J Pathol 2019, 189:1526-1535

31. Becker BF, Chappell D, Jacob M: Endothelial glycocalyx and coronary vascular permeability: the fringe benefit. Basic Res Cardiol 2010, 105:687-701

32. Luft JH: Fine structures of capillary and endocapillary layer as revealed by ruthenium red. Fed Proc 1966, 25:1773-1783

33. Rehm M, Zahler S, Lotsch M, Welsch U, Conzen P, Jacob M, Becker BF: Endothelial glycocalyx as an additional barrier determining extravasation of $6 \%$ hydroxyethyl starch or $5 \%$ albumin solutions in the coronary vascular bed. Anesthesiology 2004, 100: $1211-1223$

34. Reitsma S, Slaaf DW, Vink H, van Zandvoort MA, oude Egbrink MG: The endothelial glycocalyx: composition, functions, and visualization. Pflugers Arch 2007, 454:345-359

35. Woodcock TE, Woodcock TM: Revised Starling equation and the glycocalyx model of transvascular fluid exchange: an improved paradigm for prescribing intravenous fluid therapy. $\mathrm{Br} \mathrm{J}$ Anaesth 2012, 108:384-394

36. Hagiwara S, Iwasaka H, Matsumoto S, Noguchi T: High dose antithrombin III inhibits HMGB1 and improves endotoxin-induced acute lung injury in rats. Intensive Care Med 2008, 34:361-367

37. Ware LB, Matthay MA: The acute respiratory distress syndrome. N Engl J Med 2000, 342:1334-1349

38. Martin JV, Liberati DM, Diebel LN: Disparate effects of catecholamines under stress conditions on endothelial glycocalyx injury: an in vitro model. Am J Surg 2017, 214:1166-1172

39. Enuka Y, Hanukoglu I, Edelheit O, Vaknine H, Hanukoglu A: Epithelial sodium channels $(\mathrm{ENaC})$ are uniformly distributed on motile cilia in the oviduct and the respiratory airways. Histochem Cell Biol 2012, 137:339-353 